
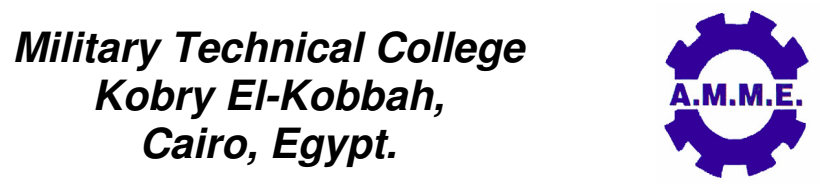
$15^{\text {th }}$ International Conference on Applied Mechanics and Mechanical Engineering.

\title{
THERMAL PERFORMANCE OF A TWO-PHASE CLOSED THERMOSYPHON
}

\author{
M. G. Wasel ${ }^{*}$, M. G. Mousa**, E. A. El-Negiry*** and A. S. El-Adl ${ }^{\star * \star *}$
}

\begin{abstract}
A two-phase closed thermosyphon (TPCT) is a device for heat transmission consisting of an evacuated tube filled with a certain amount of working fluid. Fluids with nanoparticles (particles smaller than $100 \mathrm{~nm}$ ) suspended in them are called nanofluids that they have a great potential in heat transfer enhancement. In the present study the thermal performance of conventional two phase closed thermosyphon (CT) and modified thermosyphon (MT) containing a separator in the evaporator section was investigated in case of using distilled water and Al2O3/Water nanofluid as working fluids. The effect of heat input ( $500 \mathrm{~W} \leq \mathrm{Q} \leq 1000 \mathrm{~W})$, working fluid filling ratio $(40 \% \leq$ FR $\leq 90 \%$ ), inclination angle $\left(40^{\circ} \leq \Psi \leq 90^{\circ}\right.$ ), separator diameter (ds $=25 \mathrm{~mm}, 32 \mathrm{~mm}$ and $40 \mathrm{~mm})$ and nanoparticles volume concentration $(0.5 \% \leq \varnothing \leq 2 \%)$ on thermosyphon thermal performance was experimentally investigated. The variation in Nusselt number was taken as an indication to the thermosyphon performance.
\end{abstract}

The results showed that an average increase of $8 \%$ up to $19.5 \%$ in Nusselt number can be achieved when using a separator in the evaporator section with distilled water as a working fluid. Also an average increase of $24.5 \%$ up to $164.5 \%$ in Nusselt number was achieved when using Al2O3/Water nanofluid instead of distilled water for CT. In case of using Al2O3/Water nanofluid in the presence of a separator in the evaporator, an average increase of $75 \%$ up to $197 \%$ in Nusselt number can be achieved. The experimental data are compared to the available data from previous studies and the agreement is found to be fairly good. A correlation was developed for prediction of the Nusselt number taking into consideration the effect of the varying separator diameter. The correlation agrees with the experimental data within $\pm 19.5 \%$ accuracy.

\section{KEY WORDS}

$\mathrm{Al}_{2} \mathrm{O}_{3}$ nanoparticle, Evaporator Separator, Nanofluid, Two-phase closed thermosyphon, Thermal performance.

\footnotetext{
* $\quad$ Professor, Dept. of Mech. Power, Mansoura University, Mansoura, Egypt.

** Associate professor, Dept. of Mech. Power, Mansoura University, Mansoura, Egypt.

*** Lecturer, Dept. of Mech. Power, Mansoura University, Mansoura, Egypt.

$\star * \star * \quad$ Graduate student, Dept. of Mech. Engineering, Higher Technological Institute, Tenth of Ramadan City, Egypt. Tel: +02 01224566764, Email: ahmed.s.eladl@hti.edu.eg.
} 


\section{NOMENCLATURE}

\begin{tabular}{|c|c|c|c|}
\hline$A$ & Area, $\mathrm{m}^{2}$. & \multicolumn{2}{|c|}{ Greek symbols } \\
\hline $\mathrm{Cp}$ & $\begin{array}{l}\text { Specific heat at constant pressure, } \\
, \mathrm{J} / \mathrm{kg}^{\circ} \mathrm{C}\end{array}$ & $\Delta \mathrm{T}$ & temperature Difference, ${ }^{\circ} \mathrm{C}$ \\
\hline CT & Conventional thermosyphon & $\varnothing$ & $\begin{array}{l}\text { nanoparticle volume fraction } \\
\text { (ratio of nanoparticles volume } \\
\text { to total volume) }\end{array}$ \\
\hline $\mathrm{D}$ & Thermosyphon Diameter, $\mathrm{m}$ & $\mu$ & dynamic viscosity, $\left(\mathrm{Ns} / \mathrm{m}^{2}\right)$ \\
\hline FR & $\begin{array}{l}\text { Filling ratio (the ratio of the liquid } \\
\text { volume to the evaporator volume) }\end{array}$ & $\rho$ & density, $\left(\mathrm{kg} / \mathrm{m}^{3}\right)$ \\
\hline $\mathrm{h}$ & Heat transfer coefficient, $\mathrm{W} / \mathrm{m}^{2}{ }^{\circ} \mathrm{C}$ & $\Omega$ & ohm \\
\hline K & Thermal Conductivity, $\mathrm{W} / \mathrm{m}^{\circ} \mathrm{C}$ & $\Psi$ & inclination angle,(degree) \\
\hline $\mathrm{L}$ & Length, m & \multicolumn{2}{|c|}{ Subscript } \\
\hline m & Mass flow rate, $\mathrm{kg} / \mathrm{s}$ & av & average \\
\hline$m_{p}$ & Nanoparticles mass, kg & bf & base fluid \\
\hline MT & modified thermosyphon & $\mathrm{ca}$ & condenser average \\
\hline $\mathrm{n}$ & number & $\mathrm{CW}$ & cooling water \\
\hline $\mathrm{Nu}$ & Nusselt number & cwi & inlet cooling water \\
\hline q" & Input Heat flux, $\mathrm{W} / \mathrm{m}^{2}$ & cwo & outlet cooling water \\
\hline $\mathrm{Q}_{\mathrm{av}}$ & Thermosyphon heat input, W & $\mathrm{e}$ & evaporator \\
\hline$Q_{\text {rej }}$ & $\begin{array}{l}\text { Rate of heat removal from the } \\
\text { condenser section, } W\end{array}$ & ea & evaporator average \\
\hline$Q_{s p}$ & $\begin{array}{l}\text { Heat generation rate supplied by } \\
\text { electric heaters, W). }\end{array}$ & eff & effective \\
\hline r & electric resistance, $\Omega$ & $\mathrm{h}$ & heater \\
\hline $\mathrm{R}$ & thermal Resistance , ${ }^{\circ} \mathrm{C} / \mathrm{W}$ & I & liquid \\
\hline $\mathrm{T}$ & temperature, ${ }^{\circ} \mathrm{C}$ & 0 & outer \\
\hline TPCT & two phase-closed thermosyphon & $p$ & nanoparticles \\
\hline $\mathrm{v}$ & volume, $\mathrm{m}^{3}$ & rej & rejected \\
\hline V & $\begin{array}{l}\text { applied voltage across the electric } \\
\text { heater terminals, volt }\end{array}$ & te & evaporator thermocouple \\
\hline $\mathrm{X} / \mathrm{L}$ & dimensionless axial position & $\mathrm{t}$ & total \\
\hline
\end{tabular}

\section{INTRODUCTION}

Two-phase closed thermosyphons (TPCTs) are enclosed, passive two-phase heat transfer devices that make use of the highly efficient thermal transport process of evaporation and condensation to maximize the thermal conductance between a heat source and a heat sink. The main advantage of TPCTs is that no mechanical pumping or external power is needed, also they are proven to be very effective, low cost, simple structure and reliable heat transfer devices for applications in many thermal management and heat recovery systems. They are used in many applications including but not limited to passive ground/road anti-freezing, spacecraft thermal control, power generation, air conditioning systems, water heater, solar collectors, turbine blade cooling, waste heat recovery applications and highperformance electronics thermal management. As illustrated in Fig. 1, heat which is 
added to the bottom portion of a thermosyphon (evaporator) tends to vaporize the working fluid. During this phase change process, the fluid picks up the heat associated with its latent heat of vaporization.

Because the vapor in the evaporator region is at a higher temperature, and hence at a higher pressure than the vapor in the condenser, the vapor rises and flows upward through the adiabatic section to the cooler condenser where it gives up its latent heat of vaporization. The condensate forms a liquid film which flows downwards to the evaporator. In contrast to the conventional heat pipes that use capillary force to return the liquid to evaporator, a thermosyphon uses gravitational forces to return the condensate to the evaporator where it can be vaporized again. This process of evaporation and condensation of the working fluid repeats itself continuously, as long as heat is supplied to the evaporator and an opportunity for its removal from the condenser exists.

The nanofluid is a colloidal suspension with nanoparticles dispersed uniformly in base fluid, and has been shown to enhance the thermal conductivity and convective heat-transfer performance of the base liquid. Several published literature have mainly focused on the prediction and measurement techniques in order to evaluate the different properties of nanofluids $[6,11,18$, and 20].

Key factors affecting on thermal performance of a TPCT are: filling ratio (FR), aspect ratio (AR), inclination angle, operational temperature, pressure and working fluid. Many researchers have studied these factors. $[1,5]$. Many investigations were carried out in order to enhance TPCT performance. These studies can be classified in two main approaches. Some researches focused on using more efficient working fluid to increase the thermosyphon performance and in another approach the design, mechanical and surface modification are the main strategy to enhance the TPCT performance.

Turning to first sort of research. Ong et al. [4] conducted experiments to study the thermal performance of a thermosyphon filled with R-134a. The effects of temperature difference between bath and condenser section, fill ratio and coolant mass flow rates on the performance of the thermosyphon were determined. The experimental results indicated that the heat flux transferred increased with increasing coolant mass flow rate, fill ratio and temperature difference between bath and condenser section. Jouhara et al. [12] experimentally investigated the performance of thermosyphons charged with water as well as the dielectric heat transfer liquids FC84, FC-77 and FC-3283. Generally the thermal performance of the water - charged thermosyphon outperformed the other three working fluids in both the effective thermal resistance as well as maximum heat transport capabilities. Kannan et al. [14] investigated experimentally the effect of different working fluids on the thermal performance of TPCT. Distilled water, ethanol, methanol and acetone were employed as working fluids. It was found that the maximum heat transport capability was observed for water at all operating temperature higher than $40^{\circ} \mathrm{C}$. However the methanol was found to have higher heat transport capability if the operating temperature was lower than $30^{\circ} \mathrm{C}$. 
In the recent years with more scientific attention in using nanofluids for different purposes, many researches have been focused to employ these fluids in TPCT. The enhancement of TPCT thermal efficiency with nanofluids was reported by Paramatthanuwat et al. [17], they investigated experimentally the effect of using silver nanofluid (De lonize water mixed with silver nano and particles less than 100 $\mathrm{nm}$.) on heat transfer characteristics of a two-phase closed thermosyphon at normal operating condition. It was found that, the heat transfer rate using silver nanofluids at all filling ratio was better than with pure water. In another research, Noie et al. [9] used nanofluids of aqueous $\mathrm{Al}_{2} \mathrm{O}_{3}$ nanoparticles suspensions in various volume concentration of $1-3 \%$ in a two-phase closed thermosyphon as working media. Their experimental results showed that for different applied power inputs, the efficiency of the thermosyphon increased up to $14.7 \%$ when $\mathrm{Al}_{2} \mathrm{O}_{3} /$ water nanofluid was used instead of pure water. On the other words, they concluded that it is possible to reach lower thermal resistance in a two-phase closed thermosyphon using nanofluids.

Liu et al. [19] carried out an experimental study to understand the heat transfer performance of a miniature thermosyphon using water-based carbon nanotube (CNT) suspensions as a working fluid. Experimental results showed that CNT suspensions can apparently improve the thermal performance of the thermosyphon. In a recent study, Huminic et al. [21] conducted an experimental study on the effect of using iron oxide - nanofluid as a working fluid on the thermal performance of a two phase closed thermosyphon. The tested concentration levels of nanoparticles were $0 \%, 2 \%$, and $5.3 \%$. The results showed that addition of iron oxide nanoparticles in water presented improved thermal performance compared with the operation with deionized water.

As was mentioned before, a considerable work had been done on the design, mechanical and surface modification for improving TPCT performance. Amatachaya et al. [16] investigated experimentally the effect of cross-sectional geometries, filling ratio, and aspect ratio on thermal performance of a two-phase closed thermosyphon at different rates of heat input. Two cross-sectional geometries of thermosyphon (circular and flat) were used. Joudi et al. [2] modified the TPCT design to suppress the vapor-liquid interaction by introducing a physical barrier at the adiabatic section of the heat pipe. The experimental program included five inclination angles, three heat pipe lengths with a common diameter at constant evaporator and condenser lengths. The performance of the modified heat pipes was compared to a reference gravity assisted heat pipe.

Rahimi et al. [15] investigated experimentally the effect of the condenser and evaporator resurfacing on overall performance of a $1 \mathrm{~m}$ height TPCT. The thermosyphon performances for plain and modified thermosyphon were studied. Another experimental investigation was carried out by Baojin et al. [8] to compare the heat transfer characteristics of titanium/water two-phase closed thermosyphon with the same geometry of a copper/water thermosyphon. Their results showed that there are no remarkable differences in heat transfer coefficients in the evaporator section between these thermosyphon. However, the observed heat transfer coefficient in condenser of $\mathrm{Ti} / \mathrm{H}_{2} \mathrm{O}$ thermosyphon was about 2-3 times more than that of $\mathrm{Cu} / \mathrm{H}_{2} \mathrm{O}$ one. Abou-Ziyan et al. [3] studied the performance of TPCT under stationary and vibrated conditions. Water and R-134a were used as working fluids. The effect of 
vibration is to deteriorate the water thermosyphon performance below the boiling limit by $5-20 \%$ and enhance it at the onset of boiling limit by almost the same ratio over the examined range of input heat flux. Minor or no effect is experienced with R134a below the boiling limit and enhancement up to $250 \%$ existed above the boiling limit. In another research, Srimuang et al. [10] investigated experimentally the heat transfer characteristics of a vertical flat thermosyphon (VFT). Several tests were performed to assess the effects of filling ratios, hydraulic radius, working fluid, and aspect ratio at a vertical orientation on the heat transfer characteristics of the VFT. The VFT performance was compared with that of the conventional thermosyphon (CT). It was noticed from these previous studies that the design, mechanical and surface modifications of a TPCT resulted in the increase in thermal performance of TPCTs.

The aim of the present study is to investigate the thermal performance of a conventional two-phase closed thermosyphon (CT). Also the thermal performance of a modified thermosyphon (MT) containing a separator in the evaporator section is evaluated and compared with that of the conventional thermosyphon (CT). The effect of using nanofluid $\left(\mathrm{Al}_{2} \mathrm{O}_{3} /\right.$ water) as working fluid for both thermosyphons is investigated and compared with the performance for both thermosyphon when distilled water as a working fluid.

\section{EXPERIMENTAL SETUP AND PROCEDURE}

The experimental set-up is designed and constructed to study the thermal performance of a TPCT is shown in Fig. 2. The studied thermosyphon consists of three classical sections including; an evaporator, an adiabatic section and a condenser. This thermosyphon has a length of $1200 \mathrm{~mm}$ with an internal and external diameter of 50 and $54 \mathrm{~mm}$, respectively. The length of the evaporation, adiabatic and condensation sections are design to be 40,36 and $40 \mathrm{~cm}$, respectively. In addition, a $2 \mathrm{~cm}$ space is left at the top and the bottom of tube for end caps. The vacuum is established in the thermosyphon by using a vacuum pump (15) through the vacuum line (12). The condenser is a double pipe heat exchanger where the inner pipe is the thermosyphon condenser section and the outer pipe representing the cooling jacket (4) is constructed from PVC tube with $48 \mathrm{~cm}$ total length, with internal and external diameter of $78 \mathrm{~mm}$ and $88 \mathrm{~mm}$ respectively. The thermosyphon is sealed from both ends by two end caps $(13,16)$ each is provided by two O-rings to prevent air leakage and high temperature silicon paste is used to make a gasket between the cap and the inner surface of the thermosyphon pipe to facilitate the caps mounting, protect the caps from high temperature and to provide more protection from air leakage. The evaporator is heated using five separate heaters (18) with nominal power of $500 \mathrm{~W}$ each. The heat input to the evaporator is adjusted using an electrical autotransformer (VARIAC) with a maximum heat input of $2500 \mathrm{~W}$. The modified thermosyphon (6) contained a separator (11) in the evaporator section. The separator tubes are made from PVC with $420 \mathrm{~mm}$ total length, $20 \mathrm{~mm}$ is left to enable fixing the separator in the lower end cap. Both thermosyphons are heavily insulated with a layer of $50 \mathrm{~mm}$ thick glass wool thermal insulation followed by reflective aluminum foil sheet to ensure minimum heat loss. The required amount of working is charged to the thermosyphon through the charging line (1). Digital 
multimeter (8) is used for electrical measurements. Axial wall temperature of the thermosyphon is measured by twelve chromel (nickel-chromium alloy) / alumel (nickel-aluminum alloy) thermocouples (type K) with $0.315 \mathrm{~mm}$ wire diameter. Six thermocouples are mounted on the evaporator, four on the condenser and two on the adiabatic section. Also two precise thermometers are used in the condenser section to read the input and output temperature of the cooling water. All the thermocouples are connected to temperature recorder through a multiswitch arrangement. The configuration and location of thermocouples on the TPCT are shown in Fig. 3. A bourdon tube pressure gage is mounted on the condenser end cap to measure the system internal pressure. The liquid filling ratios (the ratio of the liquid volume to the evaporator volume) were $40 \%, 50 \%, 55 \%, 60 \%$ and $90 \%$ respectively.

The volume fraction and density of nanoparticles in suspension are defined as follow:

$$
\begin{aligned}
& \varnothing=\frac{v_{p}}{v_{t}} \\
& \rho_{p}=\frac{m_{p}}{v_{p}} \\
& v_{t}=v_{b f}+v_{p}
\end{aligned}
$$

where: $\varnothing$ is nanoparticle volume fraction $\rho_{p}$ is the nanoparticles density $\left(\mathrm{kg} / \mathrm{m}^{3}\right), \mathrm{m}_{\mathrm{p}}$ is mass of nanoparticles $(\mathrm{kg}), v_{p}$ is the volume of nanoparticles $\left(\mathrm{m}^{3}\right), v_{t}$ is the total volume and $v_{b f}$ is the base fluid volume $\left(\mathrm{m}^{3}\right)$.

The Nanofluid transport and thermal properties are quite different from the base fluid. By assuming that the nanoparticles are well dispersed within the base fluid (i.e. that their spatial concentration is uniform throughout the domain), effective density and thermal capacity of nanofluids are calculated using some classical formulas which are mentioned by A. Mokmeli et al. [11], M. Chandrasekar et al.[13] and Eiyad AbuNada et al. [7].

$\rho_{\text {eff }}=(1-\varnothing) \rho_{\mathrm{bf}}+\varnothing \rho_{\mathrm{p}}$

$\rho_{\text {eff }} C p_{\text {eff }}=(1-\varnothing) \rho_{\text {bf }} C p_{b f}+\varnothing \rho_{p} C p_{p}$

where: $\rho_{\text {eff }}$ is the nanofluid effective density $\left(\mathrm{kg} / \mathrm{m}^{3}\right), \rho_{b f}$ is the base fluid density $\left(\mathrm{kg} / \mathrm{m}^{3}\right), C p_{\text {eff }}$ is the effective specific heat, $\left(\mathrm{J} / \mathrm{kg} .{ }^{\circ} \mathrm{C}\right), C p_{b f}$ is the base fluid specific heat, $\left(\mathrm{J} / \mathrm{kg} .{ }^{\circ} \mathrm{C}\right)$ and $\mathrm{Cp}_{\mathrm{p}}$ is the nanoparticles specific heat, $\left(\mathrm{J} / \mathrm{kg} .{ }^{\circ} \mathrm{C}\right)$. There exist few theoretical formulas that can be used to estimate particle suspension viscosities. Almost all such formulas have been derived from the pioneering work of Einstein (1906). The equation based on the assumption of a linearly viscous fluid containing dilute, suspended, spherical particles is presented in Refs. [11, 21]. The Einstein formula obtained was:

$$
\mu_{\text {eff }}=\mu_{\mathrm{bf}}(1+2.5 \varnothing)
$$


Einstein's formula is found to be valid for relatively low particle volume fractions $\varnothing \leq$ $2 \%$. Beyond this value, it underestimates the effective viscosity of the mixture. Brinkman has modified this equation to a more generalized form [7 and 20] which is defined as follows:

$\mu_{\mathrm{eff}}=\frac{\mu_{\mathrm{bf}}}{(1+\mathrm{c})^{2 \cdot 3}}$

where: $\mu_{\text {eff }}$ is the nanofluid effective viscosity, $\left(\mathrm{Ns} / \mathrm{m}^{2}\right)$ and $\mu_{\mathrm{bf}}$ is the base fluid viscosity, $\left(\mathrm{Ns} / \mathrm{m}^{2}\right)$.

The thermal conductivity of $\mathrm{Al}_{2} \mathrm{O}_{3}$ /water nanofluid was developed by Pak and Cho based on the result of Masuda et al. [18 and 20] the empirical equation is as follows:

$\mathrm{k}_{\mathrm{eff}}=\mathrm{k}_{\mathrm{bf}}(1+7.4 \varnothing)$

where: $k_{\text {eff }}$ is the nanofluid effective thermal conductivity $\left(\mathrm{W} / \mathrm{m}^{\circ} \mathrm{C}\right)$ anf $k_{b f}$ is the base fluid thermal conductivity $\left(\mathrm{W} / \mathrm{m}^{\circ} \mathrm{C}\right)$.

The experimental runs are executed according to the following steps:

- The thermosyphon is oriented vertically $\left(\theta=90^{\circ}\right)$.

- The thermosyphon is evacuated and charged with a certain predetermined amount of working fluid.

- Water is circulated in the cooling jacket.

- The supplied electrical power is adjusted at the desired value through the manual step-down voltage regulator and by monitoring the digital multimeter.

- Enough time is allowed for the temperatures at various locations along the heat pipe to reach steady state before changing any parameter. It is noticed, that the steady state condition is achieved after a time period about 90 minutes when the thermosyphon is operated from cold state, after that steady state condition is considered to be established when the temperatures are constant and each thermocouple fluctuated within no more than $0.2^{\circ} \mathrm{C}$. After that, the power input, condenser water flow rate, temperatures at the various locations and thermosyphon pressure are all recorded as follows:

a) The readings of thermocouples at the thermosyphon surface are recorded by changing the selector switch dial to meet all thermocouples one after another. Also the reading of the inlet and outlet cooling water temperatures are taken from the thermometers.

b) The voltage and current of the heater are measured to determine the value of applied heat rate.

c) The internal pressure is recorded using pressure gage.

- After the end of the above run, power is changed to another value, and then step 4 is repeated.

- After all measurements are taken; the value of inclination angle is changed to the desired value. The power input, condenser water flow rate, temperatures at the various locations and thermosyphon pressure are all recorded then step 3 is repeated. 
- Once an experimental test is accomplished, the power input is turned off and the condensing water is allowed to flow through the water jacket for about 45-60 min. Thus, the thermosyphon is cooled to ambient temperature and set ready for the next experiment.

- The thermosyphon is charged with another adequate amount of working fluid. Then steps from 1 to 5 are repeated.

- When using nanofluid as a working fluid, the first step is the perpetration of nanoparticles. In the present study, aluminum oxide (Al2O3) nanoparticles prepared by El-Gomhoria, co., Egypt are used. The physical characteristic of Al2O3 nanoparticles used in this study was presented in Table 1.

- These nanoparticles are dispersed in distilled water by without using any dispersant or stabilizer to prevent any possible changes of chemical properties of the nanofluid due to presence of additions. Nanofluids of $0.5 \%, 1.0 \%, 1.5 \%$, and $2 \%$ volume fraction of particles are prepared. The volume fraction and density of nanoparticles in suspension are defined as follow:

$\varnothing=\frac{v_{p}}{v_{w i}}$

$\rho_{p}=\frac{m_{p}}{v_{p}}$

So the required mass of nanoparticles is determined as:

$m_{p}=\varnothing \times v_{w f} \times \rho_{p}$

After measuring the equivalent volume to the required mass of nanoparticle powder, they were mixed with distilled water in a flask for about 1 hour before injection of nanofluid into the working fluid vessel. No precipitation of nanoparticles was observed after 6 hours of settling the suspension. After that steps from 1 to 8 were repeated.

- Thereafter, the test section is modified to perform the thermosyphon with evaporator separator configuration. This configuration allows the study the effect of evaporator separator and separator size on the performance of closed twophase thermosyphon. The three separators used all of $400 \mathrm{~mm}$ length and with diameters $25 \mathrm{~mm}, 32 \mathrm{~mm}$, and $40 \mathrm{~mm}$ respectively. The steps from 1 to 9 were repeated for each one of the separators used.

\section{DATA REDUCTION}

The obtained experimental data of temperature and power are used to calculate the heat rate, the heat transfer coefficient and Nusselt number. At steady state condition, the produced heat generated by the electrical heating is given by the equation:

$\mathrm{Q}_{\mathrm{sp}}=\left(\frac{\mathrm{v}_{\mathrm{h}}{ }^{\mathrm{2}}}{\mathrm{v}_{\mathrm{h}}}\right) \times \mathrm{n}_{\mathrm{h}}$ 
where, $Q_{\mathrm{sp}}$ is the heat generation rate supplied by electric heaters $(W) . V_{h}$ is the applied voltage across the electric heater terminals (Volt). $r_{h}$ is the heater resistance $(\Omega)$ and $n_{h}$ is the number of heaters.

The evaporator surface area is calculated according to the following equation:

$A_{e}=\pi \times D_{0} \times L_{e}$

where $A_{e}$ is the evaporator surface area $\left(m^{2}\right), D_{0}$ is the thermosyphon outer diameter $(m)$ and $L_{e}$ is the evaporator height $(m)$.

The rate of heat removal from the condenser section was obtained from the following relation:

$$
\mathrm{Q}_{\mathrm{rej}}=\dot{\mathrm{m}}_{\mathrm{cw}} \times \mathrm{C}_{\mathrm{p}} \times\left(\mathrm{T}_{\text {c.w.o }}-\mathrm{T}_{\text {c.w. }}\right)
$$

where, $Q_{\text {rej }}$ is the rate of heat removal from the condenser section $(W) . m_{\mathrm{sw}}$ is the cooling water mass flow rate, $(\mathrm{Kg} / \mathrm{s}) . \mathrm{C}_{\mathrm{p}}$ is the specific heat at constant pressure, $\left(\mathrm{J} / \mathrm{Kg}{ }^{\circ} \mathrm{C}\right), T_{\text {c.w.o }}$ is the cooling water outlet temperature, $\left({ }^{\circ} \mathrm{C}\right)$ and $\mathrm{T}_{\text {c.w. }}$ is the cooling water inlet temperature, $\left({ }^{\circ} \mathrm{C}\right)$. Since The heat losses from evaporator and condenser sections were assumed to be negligible. Then the heat transfer rate to the thermosyphon was taken equal to the average of the heat generation rate supplied by electric heaters and the rate of heat removal from the condenser section under steady-state conditions.

$$
\begin{aligned}
& \mathrm{Q}_{\mathrm{av}}=\frac{\mathrm{Q}_{\mathrm{gg}}+\mathrm{Q}_{\mathrm{Fej}}}{2} \\
& \mathrm{q}^{\prime \prime}=\frac{\mathrm{Q}_{\mathrm{gV}}}{A_{\mathrm{i}}}
\end{aligned}
$$

where: $Q_{a v}$ is thermosyphon heat input $(W)$ and $q^{\prime \prime}$ is the input heat flux $\left(W / m^{2}\right)$.

Thermocouples were used to measure the temperature distribution along the evaporator, adiabatic and condenser sections. The average evaporator temperature can be calculated from the following relation:

$$
\begin{gathered}
\mathrm{T}_{\mathrm{ea}}=\frac{\sum_{\mathrm{i=s}}^{\mathrm{i}=\mathrm{N}_{\mathrm{te}}} \mathrm{T}_{\mathrm{p}}}{\mathrm{N}_{\mathrm{te}}} \\
\mathrm{T}_{\mathrm{ca}}=\frac{\sum_{\mathrm{i}=\mathrm{s}}^{\mathrm{i}=\mathrm{N}_{\mathrm{ts}}} \mathrm{T}_{\mathrm{s}}}{\mathrm{N}_{\mathrm{tg}}}
\end{gathered}
$$

where: $T_{e a}$ is average evaporator temperature, $T_{e}$ is the local evaporator temperature, $n_{\mathrm{tc}}$ is the number of thermocouples at the evaporator. $T_{c a}$ is average condenser temperature, $T_{c}$ is the local condenser temperature and $n_{t e}$ is the number of thermocouples at the condenser.

The pressure gage is used to measure the pressure in the thermosyphon then the vapor temperature is obtained at this pressure. Then the temperature calculated from the following relation: 


$$
\begin{aligned}
& \Delta \mathrm{T}=\mathrm{T}_{\text {ea }}-\mathrm{T}_{\text {ca }} \\
& \mathrm{h}=\frac{\mathrm{q}^{\mathrm{n}}}{\Delta \mathrm{T}}
\end{aligned}
$$

where: $\Delta \mathrm{T}$ is the temperature difference and $\mathrm{h}$ is the heat transfer coefficient.

The Nusselt number is calculated by the following equation:

$\mathrm{Nu}=\frac{\mathrm{h} \times \mathrm{L}_{\mathrm{q}}}{\mathrm{K}_{\text {tif }}}$

\section{RESULTS AND DISCUSSION}

\section{Temperature Distribution}

\section{Effect of heat input on temperature distribution}

Figure 4 shows the distribution of axial wall temperature with dimensionless axial position for different heat input for CT using distilled water as working fluid. Generally, the value of wall temperature at all measuring points is directly proportional to the value of input heat. Due to the coolant water flow inside the cooling jacket, the temperature distribution in the condenser section is lower as expected. The fluctuation of temperature distribution in the evaporator is attributed to partial dry out of this point; the second reason is attributed to the use of five separate heaters along the heated length, as mentioned previously.

\section{Effect of filling ratio on temperature distribution}

Figure 5 represents the distribution of axial wall temperature along the conventional thermosyphon (CT) using distilled water as a working fluid for different filling ratios. Wall temperature for both thermosyphons changes with changing filling ratio at constant heat input. The average wall temperatures of evaporator section are lower when FR is $55 \%$, and was highest when FR is $40 \%$, while insignificant effect is observed in the condenser section. Moreover, it can noticed that wall temperature increases by increasing FR above $55 \%$, as increasing filling ratio tends to increase upstream vapor velocity and consequently the interfacial shear. The higher vapor shear gives the rise to the entertainment of liquid from the condensate film into the vapor core, which leaves the liquid film thin and evaporator surface may become dry resulting in a rise in wall temperature. It is clear that, the temperature distribution curves tend to have the same trend for all input heat configurations and filling ratios.

\section{Effect of inclination angle on temperature distribution}

The effect of thermosyphon orientation was investigated for inclination angles ranging from $90^{\circ}$ to $40^{\circ}$.Fig. 6 and Fig 7 show the distribution of axial wall temperature along the $\mathrm{CT}$ using distilled water as a working fluid for different values of inclination angle and the distribution of axial wall temperature along the MT with 40 $\mathrm{mm}$ separator using distilled water as a working fluid for different values of inclination 
angle respectively. From these figures it can be noticed that the difference in temperature readings between similar points and different inclination angle are relatively small especially in the condenser section. It is clear that, the temperature distribution curves tend to have different trend depending on the studied thermosyphon configurations.

For CT and MT with $25 \mathrm{~mm}$ separator the lowest temperature distribution occurs at inclination angles $45^{\circ}$ and $40^{\circ}$. In case of MTs with $32 \mathrm{~mm}$ and $40 \mathrm{~mm}$ separators the lowest temperature distribution occurs at inclination angles $90^{\circ}$ and $60^{\circ}$.

This is can be related to the fact that the amount of working fluid in case of MTs with $35 \mathrm{~mm}$ and $40 \mathrm{~mm}$ separators is smaller than that of CT and MT with $25 \mathrm{~mm}$ separator, so increasing the inclination angle above $60^{\circ}$ causes the working fluid to accumulate on the evaporator side which is in the direction of inclination that lead to insufficient wetting on the upper side of the evaporator, which can increase the possibility of dry out occurrence leading to an increase in wall temperature, especially at the evaporator section.

\section{Effect of separators diameter on temperature distribution}

Figure 8 shows the distribution of axial wall temperature along different thermosyphon configurations with different separator diameters $\left(d_{s}\right)$ using distilled water as a working fluid. It can be concluded that increasing the separator diameter lead to a decrease in axial wall temperature distribution. This is because the presence of a separator in the evaporator increase the contact between the working fluid and the heated surface that improve the distribution of the working fluid around the inner sides of the evaporator leading to a decrease in wall temperature along the thermosyphon.

\section{Effect of nanoparticles concentration on temperature distribution}

Figures 9 and 10 show the distribution of axial wall temperature along CT and MT respectively using nanofluid as a working fluid for different nanoparticles volume concentration. As shown by these figures that increasing the concentration of nanoparticles from $0.5 \%$ to $2 \%$ decreases the axial wall temperature distribution, so that the lowest temperature distribution is for nanofluid with $2 \%$ nanoparticles concentration. This may be related to the fact that nanofluids have better wettability characteristics [6] compared to distilled water leading to a decrease in wall temperature. Also it can be attributed to the turbulence effect of random motion (Brownian effect), dispersion, and fluctuation of nanoparticles especially near wall it leads to increase in the energy exchange rates and augments heat transfer rate between the fluid and the evaporator section wall [9]. Also it can be indicated that using nanofluid in the presence of a separator in the evaporator section results in lower wall temperature distribution compared with that of CT with nanofluid. This is due to the combination between the effects of both nanofluid and separator.

\section{Nusselt Number}

The heat transfer mechanism of the TPCT is an intricate complex consisting of evaporation and condensation mechanisms. These phenomena depend strongly on 
the filling ratio, type and amount of working fluid, inclination angle, thermosyphon geometry and input heat rate. Variation of $(\mathrm{Nu})$ was taken as an indication to thermal performance of the TPCT.

\section{Effect of filling ratio on Nusselt number}

Figures 11 and 12 show the variation of Nusselt number $(\mathrm{Nu})$ with filling ratio for different separator diameters and the variation of Nusselt number with filling ratio for different nanoparticles concentration respectively. It can be seen that the Nusselt number increases with increasing FR up to value of $55 \%$, where the Nusselt number starts to decrease with increasing the FR above 55\%. The filling ratio of the working fluid has a predominant effect on the thermal performance of a TPCT. The effect of filling ratio can be explored through understanding the dry-out and flooding phenomena. The dry out limit is reached in TPCT at the bottom of the evaporator when the filling volume of working fluid is very small. In this situation, the falling film of the condensate persists into the evaporator section, but its thickness approaches zero at the bottom. Therefore, the entire amount is circulating throughout the thermosyphon either as falling film or in the vapor flow, so a puddle of liquid at the bottom of the evaporator is not present. If the heat flux in the evaporator is increased dry-out begins at the bottom of the thermosyphon, and the size of the dry out will increase with the heat input. In general flooding is due to the interaction between the countercurrent liquid and vapor flows occurring at the liquid-vapor interface in the thermosyphon. As the relative velocity between the liquid and the vapor increase, the viscous shear interfacial forces retard the return of the liquid film from the condenser to the evaporator section. This will cause less flow to go to the evaporator and dry out the evaporator. The thermosyphon is said to have reached the flooding limit when the liquid flow is profited from returning to the evaporator section and the thermal fluid conditions are still steady and stable. So it can be concluded that dry-out limit occurs at small filling ratios and flooding limit occurs at large filling ratios. So, an optimum filling ratio is the filling ratio where the minimum effects of both limits occur. In this study the optimum filling ratio is $55 \%$ where the maximum Nusselt number occurs.

\section{Effect of inclination angle on Nusselt number}

Figures 13 and 14 show the variation of Nusselt number with inclination angle $(\Psi)$ for distilled water and the variation of Nusselt number with inclination angle $(\psi)$ for $\mathrm{Al}_{2} \mathrm{O}_{3}$ /Water nanofluid respectively. Maximum Nusselt number in case of CT and MT with $25 \mathrm{~mm}$ separator occurs at inclination angle of $40^{\circ}$ and $45^{\circ}$ respectively, while in case of MTs with $32 \mathrm{~mm}$ and $40 \mathrm{~mm}$ separators, the maximum Nusselt number occurs at inclination angle of $60^{\circ}$. This can be explained by the fact that in vertical position typical nucleate boiling occurs in the evaporator so, when the thermosyphon is inclined the turbulent motion of the liquid caused by the explosion of boiling bubbles caused a large amount of liquid to dash against the upper part of the thermosyphon tube. By increasing the inclination angle, the dashing tip of the liquid movement reached to the end of the condenser. In this case it is considered that the heat transfer mechanism in the condenser consists of the condensation of vapor and forced condensation by the dashing liquid. In addition the freshly condensed surface has been cleaned by the passage of the dashing liquid. Consequently the heat 
transfer rate is improved leading to increasing the thermal performance of the thermosyphon. In case of MTs with $35 \mathrm{~mm}$ and $40 \mathrm{~mm}$ separators amount of working fluid is smaller than that of CT and MT with $25 \mathrm{~mm}$ separator, so increasing the inclination angle above $60^{\circ}$ causes the working fluid to accumulate on the evaporator side which is in the direction of inclination that lead to insufficient wetting on the upper side of the evaporator, so that the liquid movement (dashing distance) lessened and the heat transfer rate decreases [1] and consequently the thermal performance of the thermosyphon.

\section{Effect of separator diameter on Nusselt number}

Figure 15 shows the variation of Nusselt number $(\mathrm{Nu})$, with separator diameter $\left(\mathrm{d}_{\mathrm{s}}\right)$ with distilled water as a working fluid for different filling ratios. Adding a separator to the evaporator section and by increasing the separator diameter improves the Nusselt number and hence the thermosyphon performance. This is because the presence of a separator in the evaporator increases the contact between the working fluid and the heated surface that enhance the boiling heat transfer. The stirring and agitation caused by the entrainment of the liquid to the heated surface is the primarily responsible for the increased heat transfer rate leading to enhanced performance. Also the separator replace the core of the liquid pool in the evaporator, so that the vapor bubbles detached from the heated surface and rising to the liquid pool take smaller distance to collapse releasing heat and improving boiling mechanism.

\section{Effect of Nanoparticles Concentration on Nusselt number}

Figure 16 shows the variation of Nusselt number $(\mathrm{Nu})$, with nanoparticles concentration $(\varnothing)$ for different filling ratio. Replacing distilled water by nanofluid and by increasing the nanoparticles concentration improves the Nusselt number and consequently the TPCT thermal performance. The thermosyphon thermal performance enhancement due to the addition of nanoparticles to the base fluid results from the following reasons. The increase of the effective thermal conductivity of nanofluid compared to that of distilled water. Addition of nanoparticles to fluid changes the heat transfer mechanism so that besides of thermal conductivity increase, Brownian motion, dispersion, and fluctuation of nanoparticles especially near wall leads to increase in the energy exchange rates and augments heat transfer rate between the fluid and the evaporator section wall. An increase in the nanoparticles volume concentration intensifies the interaction and collision of nanoparticles. Also diffusion and relative movement of these particles near the tube wall leads to rapid heat transfer from the TPCT wall to nanofluid. In other words, increasing the concentration of nanoparticles intensifies the mechanisms responsible for enhanced heat transfer. A major thermal resistance of TPCT is caused by the formation of vapor bubbles at the liquid-solid interface. Where a larger bubble nucleation size creates a higher thermal resistance that prevents the transfer of heat from the solid surface to the liquid. The suspended nanoparticles tend to bombard the vapor bubbles during the bubble formation [12 and 16]. Also during boiling a porous deposit layer of the aggregated nanoparticles is formed on the heated surface increasing the surface roughness, improve the wettability and enhances the boiling heat transfer. 


\section{Combined effect of separator and nanofluid}

Figure 17 shows the variation of Nusselt number with nanoparticles concentration ( $\varnothing$ ) for different separator diameters. Using nanofluid in the presence of a separator in the evaporator section results in enhanced Nusselt number compared with that of CT with nanofluid. This is due to the combination between the effects of both nanofluid and separator which were mentioned before.

\section{EMPIRICAL CORRELATION OF HEAT TRANSFER}

A dimensionless analysis for different factors that affect experimental heat transfer coefficient is performed to obtain dimensionless correlation as follow:

$$
\begin{aligned}
\mathrm{Nu}= & 1.59 \times 10^{-7}\left[\left(\mathrm{~K}_{\mathrm{g}}\right)^{1093}(\mathrm{FR})^{-0.078}(\mathrm{AR})^{0.066}(\mathrm{Gr})^{-1.071}\right] \\
\mathrm{K}_{\mathrm{q}} & =\frac{\mathrm{Q}_{\mathrm{av}} \mathrm{C}_{\mathrm{p}} \mathrm{L}_{\mathrm{q}}}{\mathrm{kv} \mathrm{v}^{2}} \\
\mathrm{FR} & =\frac{\mathrm{L}_{1}}{\mathrm{~L}_{\mathrm{s}}} \\
\mathrm{AR} & =\frac{\mathrm{D}_{\mathrm{i}}-\mathrm{d}_{\mathrm{s}}}{\mathrm{L}_{\mathrm{g}}} \\
\mathrm{Gr} & =\frac{\mathrm{Bg}_{\mathrm{g}} \mathrm{L}_{\mathrm{s}}^{\mathrm{s}} \Delta \mathrm{T}}{w^{2}}
\end{aligned}
$$

where, $\mathrm{FR}$ is the filling ratio, $\mathrm{Gr}$ is the Grashof number, $\mathrm{K}_{\mathrm{q}}$ and $\mathrm{AR}$ are dimensionless numbers. This empirical correlation is valid for the following ranges: $3.885 \times 10^{18} \leq \mathrm{K}_{\mathrm{q}}$ $\leq 1.085 \times 10^{20}, 40 \% \leq \mathrm{FR} \leq 90 \%, 0.025 \leq \mathrm{AR} \leq 0.125$ and $5.8 \times 10^{9} \leq \mathrm{Gr} \leq 5.51 \times$ $10^{11}$. The correlation agrees with the experimental data within $\pm 19.5 \%$ accuracy.

\section{CONCLUSION}

In the present work, the thermal performance of conventional two phase closed thermosyphon (CT) and modified thermosyphon (MT) with a separator in the evaporator section is investigated in case of using distilled water and $\mathrm{Al}_{2} \mathrm{O}_{3} /$ water nanofluid. Based on the obtained results of the present study the following conclusions may be deduced:

1- Nanofluids in all studied concentrations showed better thermal performance than distilled water for CT and MT.

2- The modified thermosyphon (MT) containing a separator in the evaporator section showed better thermal performance than conventional thermosyphon (CT).

3- MT using nanofluid as working fluid showed the best thermal performance.

4- An average increase of $8 \%$ up to $19.5 \%$ in Nusselt number can be achieved when using a separator in the evaporator section and average increase of $24.5 \%$ up to $164.5 \%$ in Nusselt number can be achieved when using nanofluid instead of distilled water. In case of using nanofluid in the presence 
of a separator in the evaporator, an average increase of $75 \%$ up to $197 \%$ in can be achieved.

5- Wall temperature distribution of the thermosyphons using nanofluid is lower than those using distilled water at different heat fluxes and wall temperature distribution of the MT is lower than CT. MT using nanofluid as working fluid has the lowest wall temperature distribution.

6- Results indicate that the nanofluid has remarkable potential as working fluid for thermosyphon of higher thermal performances.

7- Finally a correlation is developed for prediction of the Nusselt number taking into consideration the effect of the varying separator diameter. The correlation agrees with the experimental data within $\pm 19.5 \%$ accuracy.

\section{REFERENCES}

[1] Kanji Negishi and Teruo Sawada, "Heat Transfer Performance of an inclined two-phase closed thermosyphon", International Journal of Heat and Fluid Flow, Vol. 26, No. 8, 1983, pp. 1207-1213.

[2] Khalid A. Joudi, and A.M. Witwit, "Improvements of gravity assisted wickless heat pipes", Energy Conversion \& Management, Vol. 41, 2000, 2041-2061.

[3] H.Z. Abou-Ziyan, A. Helali, M. Fatouh, and M.M. Abo El-Nasr, "Performance of stationary and vibrated thermosyphon working with water and R134a", Vol. 21, 2001, pp.813-830.

[4] K.S. Ong, and M. Haider-E-Alahi, "Performance of a R-134a-filled thermosyphon", Applied Thermal Engineering, Vol. 23, 2003, pp. 23732381.

[5] S.H. Noie,"Heat transfer characteristics of a two-phase closed thermosyphon", Applied Thermal Engineering, Vol. 25, 2005, pp.495-506.

[6] Xiang-Qi Wang, and Arun S. Mujumdar," Heat transfer characteristics of nanofluids: a review", International Journal of Thermal Sciences, Vol. 46, 2007, pp. 1-19.

[7] Eiyad Abu-Nada, "Effects of variable viscosity and thermal conductivity of $\mathrm{Al}_{2} \mathrm{O}_{3}$-water nanofluid on heat transfer enhancement in natural convection", International Journal of Heat and Fluid Flow Vol. 30, 2009, pp. 679-690.

[8] Qi Baojin, Zhang Li, Xu Hong, and Sun Yan," Heat transfer characteristics of titanium/water two-phase closed thermosyphon", Energy Conversion and Management, Vol. 50, 2009, pp. 2174-2179.

[9] S.H. Noie, S. Zeinali Heris, M. Kahani, and S.M. Nowee,"Heat transfer enhancement using $\mathrm{Al}_{2} \mathrm{O}_{3}$ /water nanofluid in a two-phase closed thermosyphon", International Journal of Heat and Fluid Flow, Vol. 30, 2009, pp. 700-705.

[10] W. Srimuang, S. Rittidech, and B. Bubphachot,"Heat transfer characteristics of a vertical flat thermosyphon (VFT)", Journal of Mechanical Science and Technology, Vol. 23, 2009, pp. 2548-2554.

[11] A. Mokmeli, M. Saffar Avval, "Prediction of nanofluid convective heat transfer using the dispersion model", International Journal of Thermal Sciences, Vol. 49, 2010, pp. 471-478.

[12] Hussam Jouhara and Anthony J. Robinson, "Experimental investigation of 
small diameter two-phase closed thermosyphons charged with water, FC84, FC-77 and FC-3283", Applied Thermal Engineering Vol. 30, 2010, pp.201-211.

[13] M. Chandrasekar, S. Suresh, and A. Chandra Bose, "Experimental investigations and theoretical determination of thermal conductivity and viscosity of $\mathrm{Al}_{2} \mathrm{O}_{3} /$ water nanofluid", Experimental Thermal and Fluid Science, Vol. 34, 2010, pp.210-216.

[14] M. Kannan, and E. Natarajan,"Thermal performance of a two-phase closed thermosyphon for waste heat recovery system", Journal of applied science, Vol.10, 2010, pp. 413-418.

[15] Masoud Rahimi, Kayvan Asgary, and Simin Jesri, "Thermal characteristics of a resurfaced condenser and evaporator closed two-phase thermosyphon", International Communications in Heat and Mass Transfer, Vol. 37, 2010, pp. 703-710.

[16] P.Amatachaya, and W.Srimuang, "Comparative heat transfer characteristic of a flat two-phase closed thermosyphon (FTPCT) and a conventional twophase closed thermosyphon (FTPCT)", International Communications in Heat and Mass Transfer, Vol. 37, 2010, pp. 293-298.

[17] T. Parametthanuwat, S. Rittidech, and A. Pattiya," A correlation to predict heat-transfer rates of a two-phase closed thermosyphon (TPCT) using silver nanofluid at normal operating conditions", International Journal of Heat and Mass Transfer, Vol. 53, 2010, pp.4960-4965.

[18] Tun-Ping Teng, Yi-Hsuan Hung, Tun-Chien Teng, Huai-En Moa and How-Gao Hsu,"The effect of alumina/water nanofluid particle size on thermal conductivity", Applied Thermal Engineering , Vol.30, 2010, pp. 22132218.

[19] Zhen-hua Liu , Xue-fei Yang, Guo-san Wang and Guang-liang Guo," Influence of carbon nanotube suspension on the thermal performance of a miniature thermosyphon ", International Journal of Heat and Mass Transfer, Vol.53, 2011, pp. 1914-1920.

[20] A. Ghadimi, R. Saidur, and H.S.C. Metselaar,"A review of nanofluid stability properties and characterization in stationary conditions", International Journal of Heat and Mass Transfer, Vol.54, 2011, pp.40514068.

[21] Gabriela Huminic, Angel Huminic, Ion Morjan, and Florian Dumitrache," Experimental study of the thermal performance of thermosyphon heat pipe using iron oxide nanoparticles", International Journal of Heat and Mass Transfer, 2011. 


\section{FIGURES}

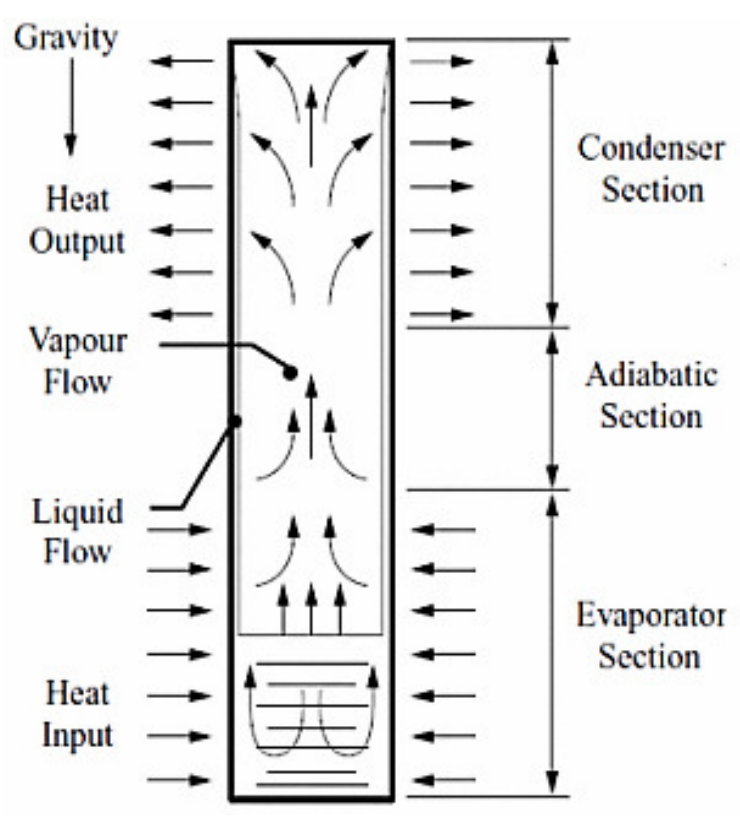

Fig. 1. Schematic diagram of a two-phase closed thermosyphon (TPCT).

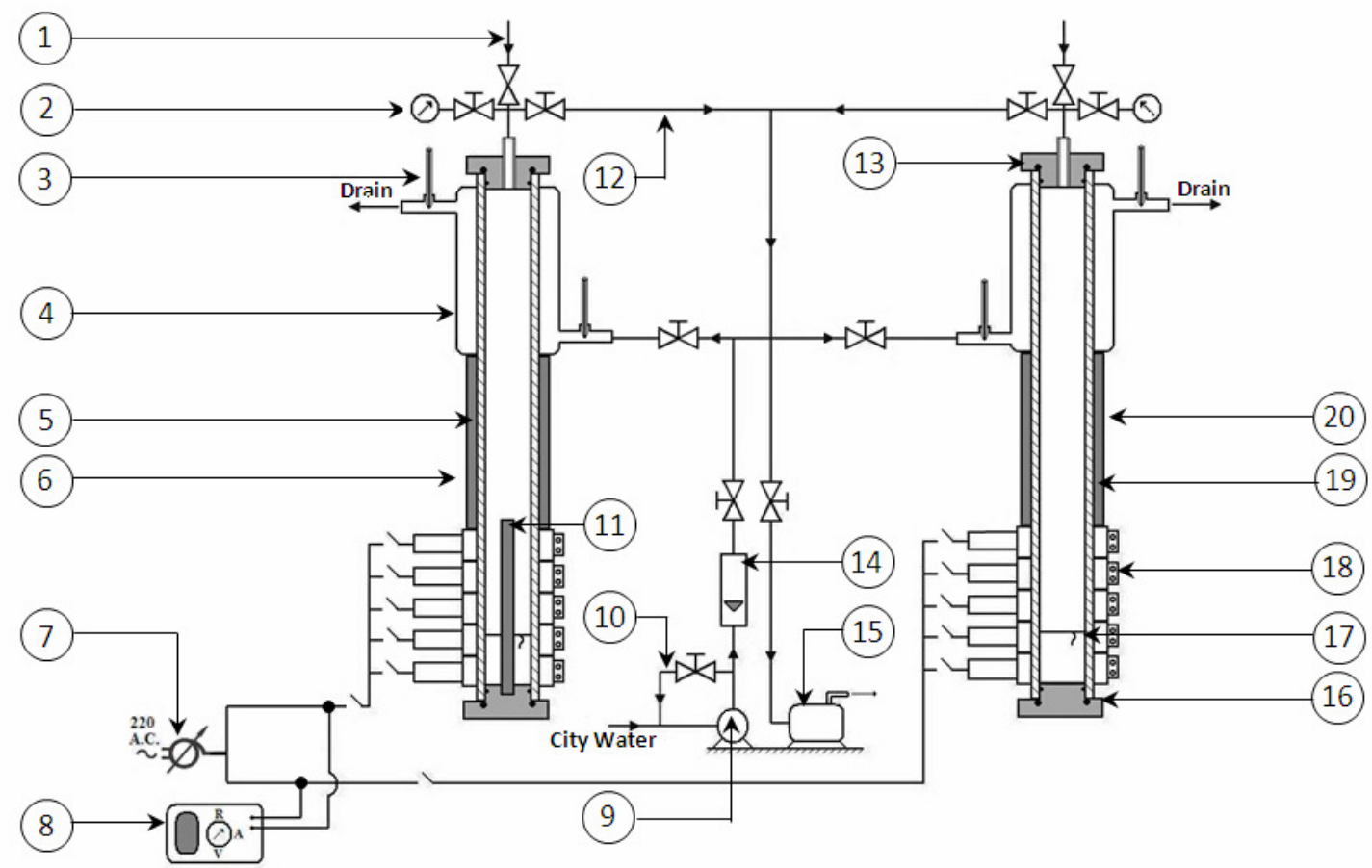

1- Feed Line, 2- Pressure gauge, 3- Thermometer, 4- Cooling jacket,

5- Adiabatic section, 6- Modified thermosyphon (MT), 7-Autotransformer (VARIAC), 8- Digital multimeter, 9- Water pump, 10- By pass. 11- Separator 12- Vacuum line, 13- Upper cap, 14- Rotameter, 15- Vacuum pump, 16- Lower cap, 17- Evaporator section, 18- Electric heater, 19- Insulation, 20- Conventional thermosyphon (CT).

Fig. 2. Schematic diagram of experimental apparatus. 


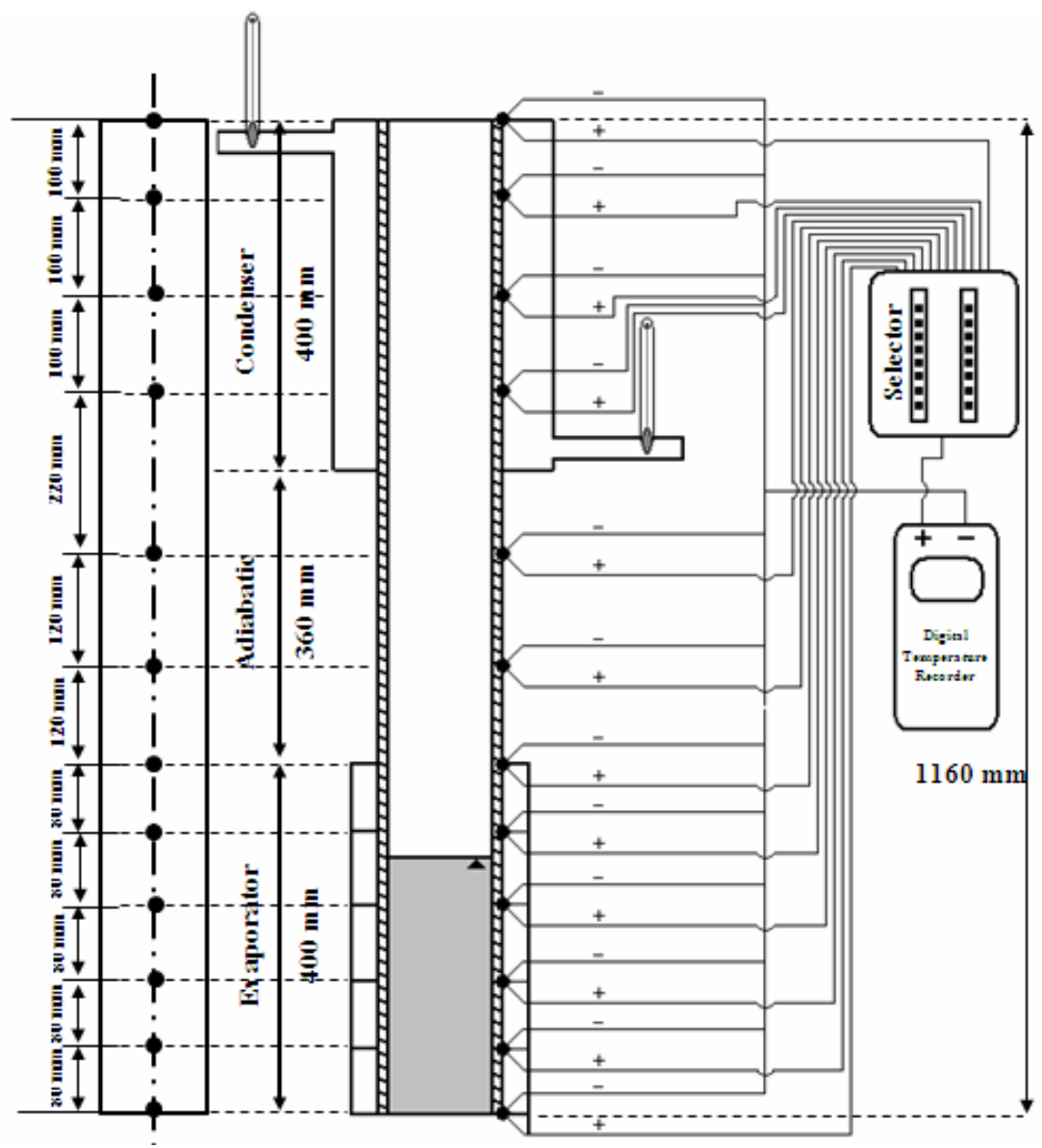

Fig. 3. Location of Thermocouples on TPCT.

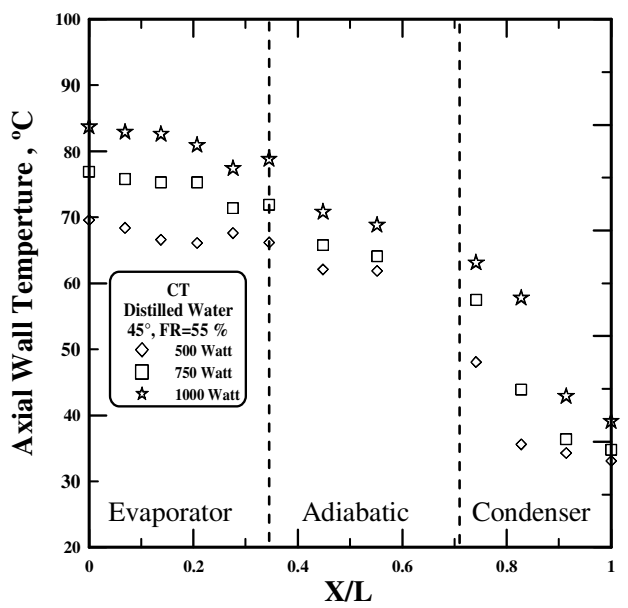

Fig. 4. Distribution of wall temperature with dimensionless axial position for different heat input for CT using distilled water as working fluid. 


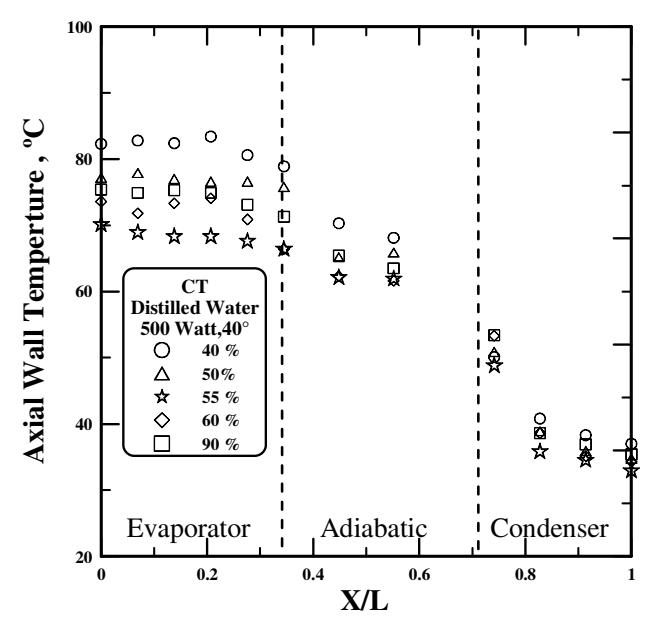

Fig. 5. Distribution of wall temperature with dimensionless axial position for different filling ratio for CT using distilled water as working fluid.

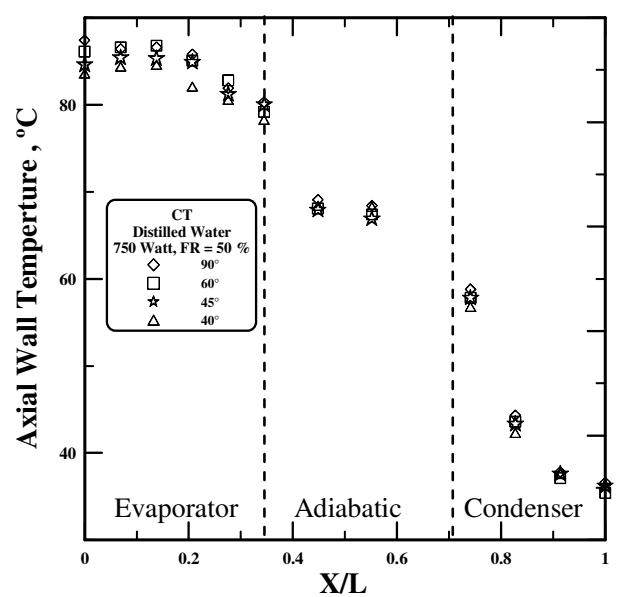

Fig. 6. Distribution of wall temperature with dimensionless axial position for different inclination angles for CT using distilled water as working fluid.

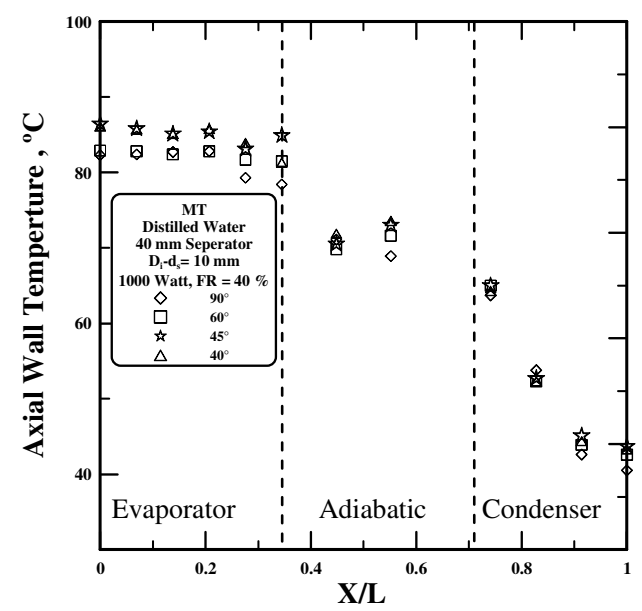

Fig. 7. Distribution of wall temperature with dimensionless axial position for different inclination angles for MT with $40 \mathrm{~mm}$ separator using distilled water as working fluid. 


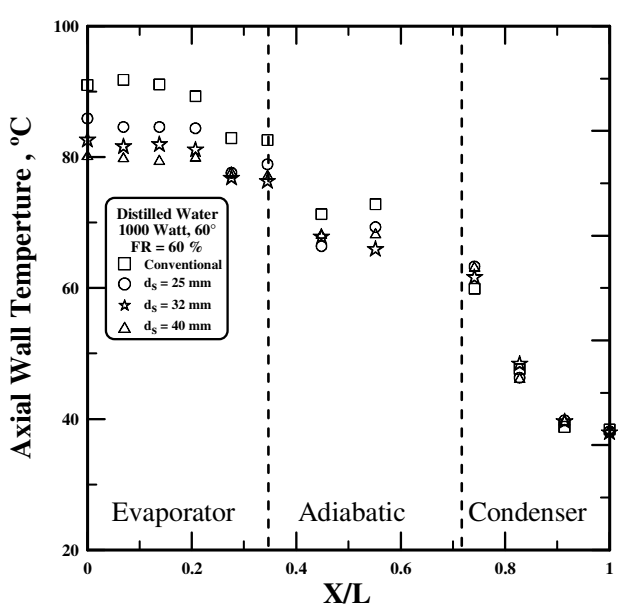

Fig. 8. Distribution of wall temperature with dimensionless axial position for different separator diameter with distilled water as a working fluid.

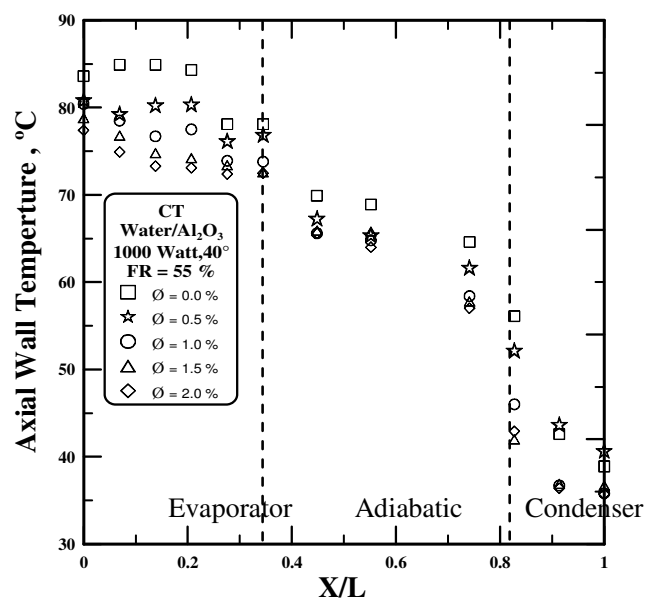

Fig. 9. Distribution of wall temperature with dimensionless axial position for different nanoparticles volume concentrations for $\mathrm{CT}$.

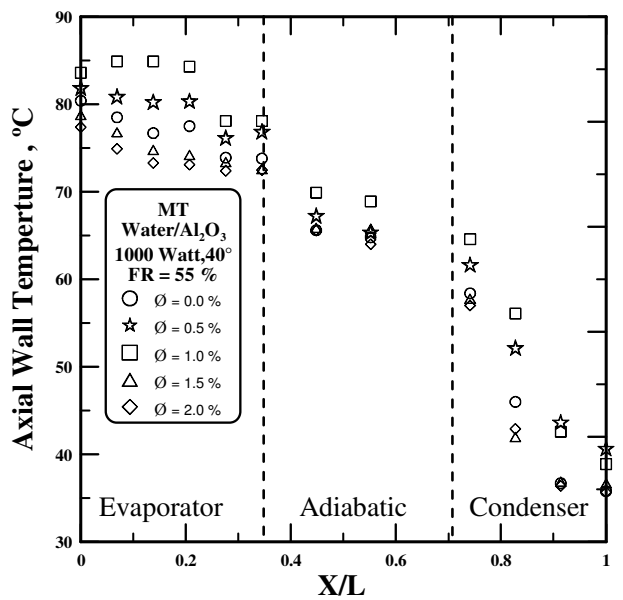

Fig. 10. Distribution of axial wall temperature with axial position for different nanoparticles volume concentrations for MT. 


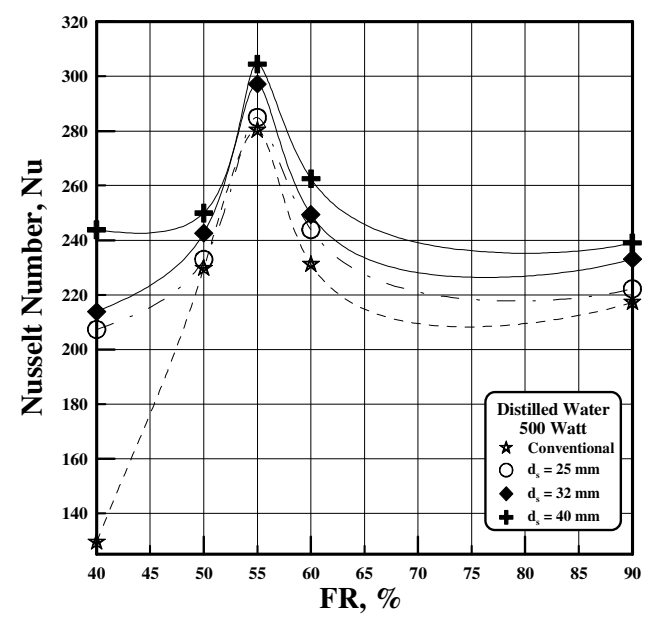

Fig. 11. Variation of Nusselt Number with filing ratio diameter for different separator diameters.

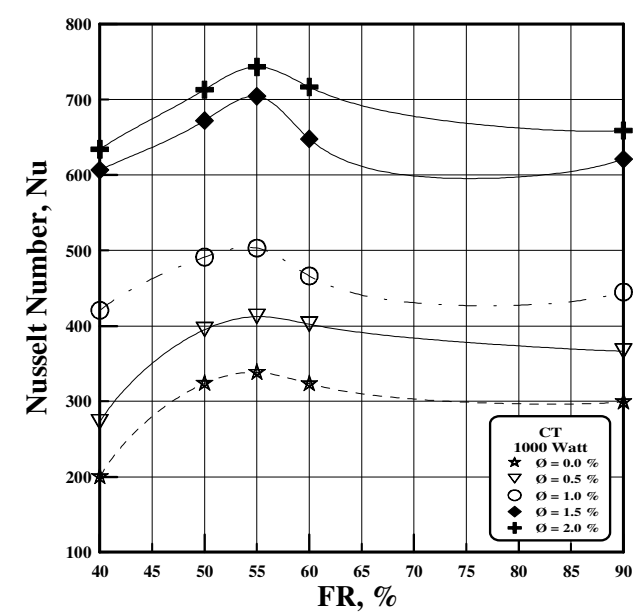

Fig. 12. Variation of Nusselt Number with nanoparticles concentration for different nanoparticles concentration.

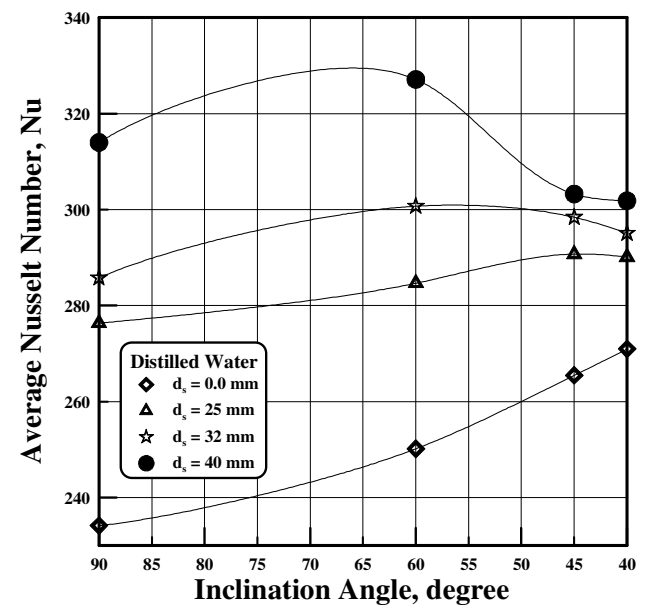

Fig. 13. Variation of Nusselt number with inclination angle for different separator diameters in case of using distilled water as a working fluid. 


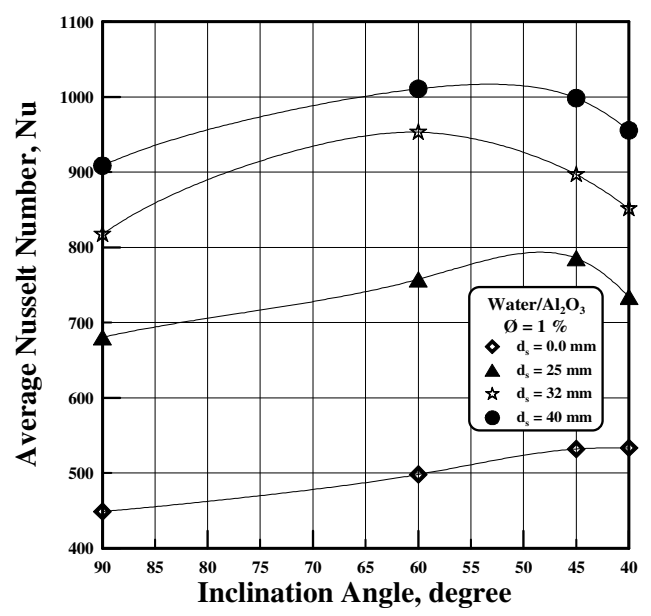

Fig. 14. Variation of Nusselt number with inclination angle for different separator diameters in case of using $\mathrm{Al}_{2} \mathrm{O}_{3} /$ Water nanofluid as a working fluid.

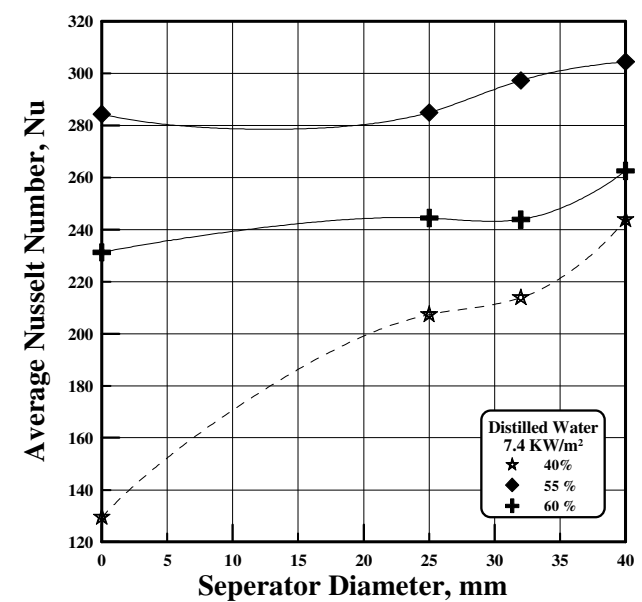

Fig. 15. Variation of Nusselt number with separators diameter for different filling ratios.

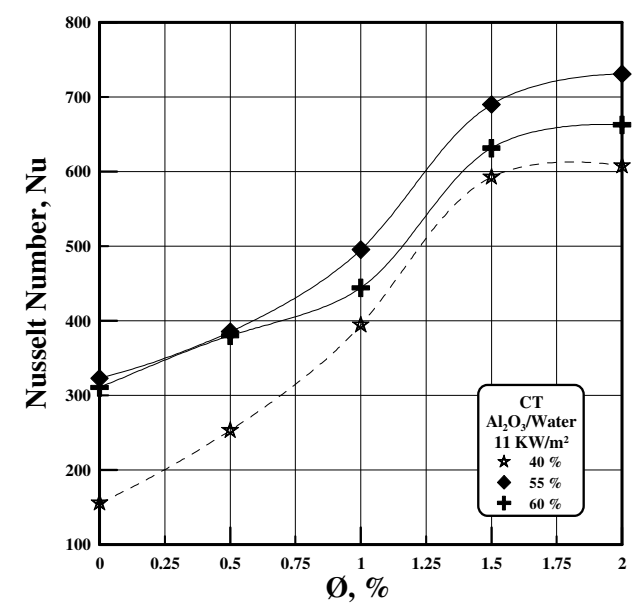

Fig. 16. Variation of Nusselt number with nanoparticles concentration for different filling ratios for $\mathrm{CT}$. 


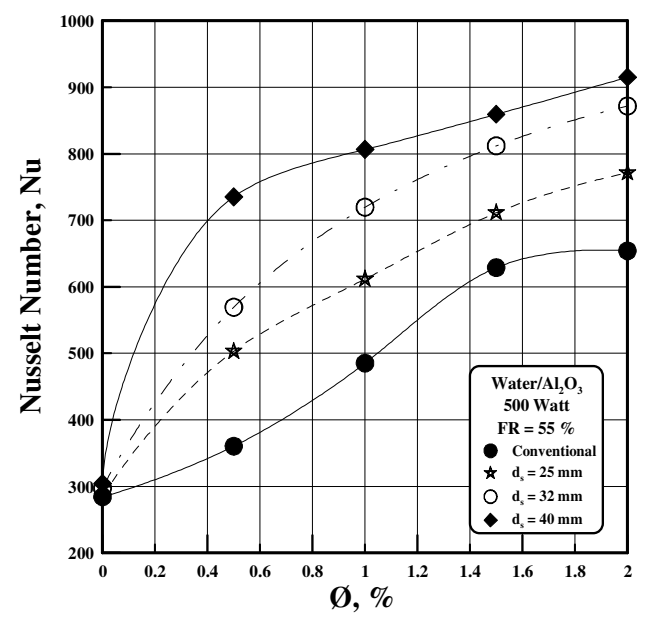

Fig. 17. Variation of Nusselt number with nanoparticles concentration for different Separator diameter.

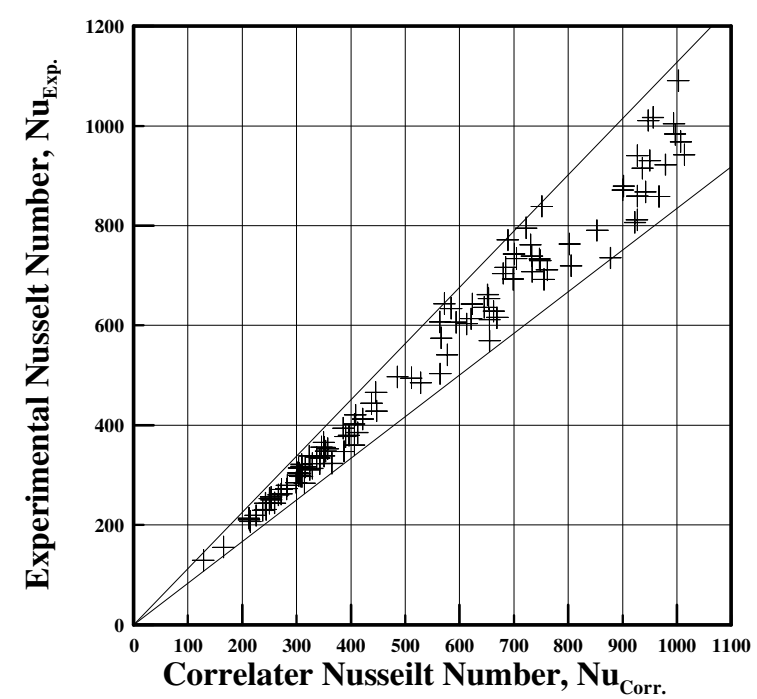

Fig. 18. Experimental Nusselt number versus correlated Nusselt number over the tested range of heat input rates. 
Table 1. Physical characteristic of Aluminum oxide $\left(\mathrm{Al}_{2} \mathrm{O}_{3}\right)$ nanoparticles used in this study

\begin{tabular}{ccccccc}
\hline Particle & $\begin{array}{c}\text { Average } \\
\text { Diameter } \\
(\mathrm{nm})\end{array}$ & $\begin{array}{c}\text { Density } \\
\left(\mathrm{Kg} / \mathrm{m}^{3}\right)\end{array}$ & $\begin{array}{c}\text { Melting } \\
\text { point }\left({ }^{\circ} \mathrm{C}\right)\end{array}$ & $\begin{array}{c}\text { Boiling } \\
\text { point }\left({ }^{\circ} \mathrm{C}\right)\end{array}$ & $\begin{array}{c}\text { Specific } \\
\text { heat } \\
\left(\mathrm{J} / \mathbf{k g} .{ }^{\circ} \mathrm{C}\right)\end{array}$ & $\begin{array}{c}\text { Thermal } \\
\text { conductivi } \\
\text { ty } \\
\left(\mathrm{W} / \mathrm{m} .{ }^{\circ} \mathrm{C}\right)\end{array}$ \\
\hline $\mathrm{Al}_{2} \mathrm{O}_{3}$ & $30-40$ & 3970 & 2054 & 3000 & 880 & 46 \\
\hline
\end{tabular}

Table 2. Separators Specifications

\begin{tabular}{c|c|c|c}
\hline $\left.\begin{array}{c}\text { Separator } \\
\text { diameter(d }\end{array}\right), \mathbf{m m}$ & $\begin{array}{c}\text { Separator length, } \\
\mathbf{m m}\end{array}$ & $\begin{array}{c}\text { Thermosyphon } \\
\text { inner Diameter } \\
\left(\mathbf{D}_{\mathbf{i}}\right), \mathbf{m m}\end{array}$ & Di-ds, $\mathbf{m m}$ \\
\hline 25 & 400 & 50 & 25 \\
\hline 32 & 400 & 50 & 18 \\
\hline 40 & 400 & 50 & 10 \\
\hline
\end{tabular}

